\title{
Temalı Konut Projelerinde Kullanılan Reklam Dilinin Kent Yaşamındaki Postmodern Göstergeleri
}

\author{
Çiğdem Karabağ 1 \\ ORCID: 0000-0003-1590-9172
}

\author{
Esin Hasgül 2 \\ ORCID: 0000-0003-4115-1940
}

Öz

Kent ve kent nosyonu, postmodern tüketim kültürünün etkisi ile oluşan toplumsal örüntüler çerçevesinde, bu üslubu yansıtan temalı mekânlara dönüş(türül)mektedir. Postmodernizm karakterini sergileme çabası içinde kurgulanan mimari yapılanmalar, gösterge ve imajlarla bireye gerçekdışı bir yaşamın anahtarını sunmaktadır. Alman felsefeci Walter Benjamin, kapitalizmin reklam gibi dinamikleri kullanarak her türlü imgeyi kendi içine alma ve dönüştürebilme durumunu "imgeleri çalmak" olarak tanımlamaktadır. Postmodern kentteki yaşam anlayışı artık "hipergerçeklik" kavramı üzerinden temalı konut projeleri adı altında işleyen bir model kurgulamaktadır. Yapay ortamlarda kurulu kopyala-yapıştır inşası ile gerçekleşen yeni kent parçaları; Baudrillard'in rasyonel gerçekliğin yerini sentetik gerçekliğin alması olarak adlandırdığ "simülakr" kavramıyla ilişkilenmektedir. Bu doğrultuda çalışma kapsamında; 2000-2020 yılları arasında yazll ve görsel medyada yayınlanan, reklam tanıtımlarında tema içeriği olan ve İstanbul kenti özelindeki çoklu konut üretimleri incelenmektedir. Projeler konut proje görselleri, reklam metinleri ve tanıtım filmleri üzerinden seçimler yapılarak söylem analizi yöntemiyle değerlendirilmektedir. Böylelikle, postmodern tüketim kültürünün mimari üslubu eklektik bir anlayış ile çevreleyen reklam dilinin yansımalar ve yeni yaşam kültürünün göstergeleri ortaya koyulmuştur.

Anahtar Kelimeler: Postmodernizm, temal konut projeleri, tüketim kültürü, reklam dili, gösterge

\footnotetext{
${ }^{1}$ Yüksek Lisans, İstanbul Kültür Üniversitesi, E-mail: cigdemkarabag@superonline.com 2 Dr. Öğr. Üyesi, İstanbul Kültür Üniversitesi, E-mail: e.hasgul@iku.edu.tr

idealkent (c) Kent Araştırmaları Dergisi (Journal of Urban Studies) 


\title{
Postmodern Indicators of the Advertising Language Used in Themed Housing Projects in Urban Life
}

\author{
Çiğdem Karabağ ${ }^{3}$ \\ ORCID: 0000-0003-1590-9172
}

\author{
Esin Hasgül 4 \\ ORCID: 0000-0003-4115-1940
}

\begin{abstract}
City and the notion of city have transformed into themed spaces as part of social patterns formed by the effect of postmodern consumption culture. Architectural formations which are designed in effort of displaying the character of postmodernism, suggest individuals the key of an unreal life produced by images and indicators. German philosopher Walter Benjamin defined the state of capitalism as the ability to absorb and transform all kinds of instruments as "stealing images" made by using dynamics such as advertising. Concept of living in postmodern city has now defined with "hyperreality" and a model is being constructed within these themed projects. Installed copy-paste constructions as new artificial parts of city are related with the term "simulacra" which Baudrillard names as replacement of rational reality with synthetic reality. Within the scope of the study, multiple housing project productions are examined which exist in written and visual media between 2000-2020, have themed content in advertisements and locate specifically in Istanbul. Projects are evaluated with discourse analysis method by selection of examples over project images, advertisement texts and promotional films. Thus, reflections of advertising language surrounding architectural style of postmodern consumer culture with an eclectic understanding and new living culture indicators are revealed.
\end{abstract}

Keywords: Postmodernism, themed housing projects, consumption culture, advertisement language, indicator

\footnotetext{
${ }^{3}$ Master, İstanbul Kültür University, E-mail: cigdemkarabag@superonline.com

${ }^{4}$ Assist. Prof. Dr., İstanbul Kültür University, E-mail: e.hasgul@iku.edu.tr

idealkent (c) Kent Araştırmaları Dergisi (Journal of Urban Studies) 


\section{Giriş}

Kentin değişimi, mimari biçimi, tüketim bağlamında görünümü ve gündelik hayattaki etkileşimleri çerçevesinde oluşan tüm ifadeler; kentin analiz edilmesinde kullanılan etkin kavramlardır. Postmodern kent olgusunda ise, "küresel kültür" kavramı, beraberinde gelişen yeni yaşam formlarının mimari mekânları parçalı olarak bir araya getirdiği heterojen birleşimlerdir. Küresel kültürün yarattığı paradigmalar; kentleşme, postmodern yaşam biçimi ve mimari formlarla karşımıza çıkar (Akay, 2013 s.62). Yeni kültürün oluşturduğu mimari biçimlerin sosyo-kültürel yaşam alanlarına yansıyan bir hayat tarzına dönüştüğü gözlemlenmektedir (Kırılmaz ve Ayparçası, 2016). Bu bağlamda kent sahnesinde ortaya konulan bu biçimler, nihayetinde toplumun düşünsel ve kültürel imgelerinin bir araya gelmesi halidir. Postmodern kentin parçalı hali ise kentin her parçasının kendisine has özgünlüğünü ortaya çıkarmaktadır (Bal, 2018 s.81). Sosyo-kültürel yaşamlara, yaşam stillerine, bireyin toplumsal statülerine yüklenen anlamlar aracıllğ 1 ile barınma biçimleri de birer tüketim metası haline getirilmiştir. Mimarlığın nesnesi olan mekân, göstergeler sistemi ile oluşturulan tüketim unsurlarının etkin bir öğesidir (Yırtıc1, 2002). Tüketme unsurunun ayrıştırıcı etkisi, bireyin özgür iradesinden ve rasyonel ihtiyaçlarından uzaklaşılmasına yol açmaktadır. Tüketim toplumuna yönelik kavramsal çalışmaların öncülerinden olan Baudrillard "Tüketim Toplumu" isimli kitabında; tüketimin doğal gereksinimlerden ziyade, kodlar ve göstergeler üzerinden yapıldığından söz açar ve bireylerin sahte-gerçek ihtiyaç ayırımı yapmaksızın sunulan ürünleri satın alarak toplumsal bir ayrıcalık sergilediklerine inanmalarına değinir (Baudrillard, 2019). Bu söylemler çerçevesinde mimarlı̆̆ın da değişen parametreler içerisinde tüketim nesnesi haline gelmesi ile önemli bir dönüşümün gerçekleştiği söylenebilir. Özellikle 1960'ların sonlarında postmodernizm adı verilen kırılma ile tüketim çerçevesinde mimarlık söylemi yeni bir dönüşüm geçirmiştir (Yırtıcı, 2002). Postmodernizm kavramı bu noktada, çağdaş tüketim kalıpları içerisinde bir gösterge unsuru olarak, tüketip yenisine sahip olma döngüsü tanımlar. Reklamlar aracılığı ile kurgulanan yaşam tarzları ile bireyler; prestij, imtiyaz, saygınlık, refah, vb. olgulara sahip olabileceklerine inandırılır (Kırılmaz ve Ayparçası, 2016). Konut üretiminde de kitle iletişim araçları bu bağlamda önem kazanmıştır. Tüketici gereksinimlerinin ötesinde düşsel bir gerçeklik ile tasarlanan yapılar, işlevsel geçişleri ile hizmet tüketimini sağlayan mekânsal kurgulardan oluşmaktadır (Süer ve Sayar, 2002). Böylelikle işlevsel 
bir görünüme sahip olan mekânlar, sentetik bir üretim biçimiyle sonsuz sayıda yeniden üretilebilmektedir (Baudrillard, 2018, s.14-15). İşlevsel görünüme sahip bu kurgular artık bireylere konut tercihinde farklı bir yaşam sunmaktadır ve sunulan yeni yaşamda site dışındaki dünya ile etkileşim en aza indirgenmiştir. Meta-gösterge anlayışı doğrultusunda tasarlanan temalı konut projeleri ile kent ve mahalle simülasyonları, imgesel kent metaforları ve kolaj kentler yaratılmaktadır (Batı, 2008). Tüketici bu noktada, senaryosu önceden oluşturulmuş yeni yaşam kurgularını satın almaktadır. Satın alınan değer ile gündelik yaşamın estetikleştirilmesi, popüler kültür simgelerine dayalı yeni kentsel biçimlerin oluşmasına neden olmaktadır. Kapitalizmin bir aracı iletim mekanizması olan reklamcılık faaliyetleri, bu kapsamda her şeyi ve herkesi etkisizleştirmektedir (Benjamin, 1993). Ortaya konulan bu problem doğrultusunda çalışma kapsamında; 2000-2020 yılları arasında İstanbul metropol kentindeki temalı konut projeleri incelenmektedir. Yazılı ve görsel medyadan yararlanılarak tema içerikleri, proje görselleri, reklam metinleri, tanıtım sloganları ve tanıtım filmleri üzerinden seçilen 10 örnek proje analiz edilmektedir. Belirlenen örneklemdeki metin ve görsellerin analizi yapılarak postmodern yaşam biçimleri üzerinden proje metni okumaları ve haritalamaları gerçekleştirilmektedir. Elde edilen verilerin değerlendirilmesi ile yeni yaşam göstergelerinin okunması amaçlanmaktadır. Medyada kullanılan reklam dilinin kent ve konut kültürüne etkileri de bu yöntem ile irdelenmektedir.

\section{Kavramsal Çerçeve}

Kentsel ve sosyal ayrışma ile artan tüketim pratikleri, postmodern yaşam kurgularının evrilmesini önemli ölçüde etkilemektedir. Literatürde postmodernizm kavramına ilişkin ortaya konulan tanımlamalar doğrultusunda postmodern yaşam kurgusunun ifadesi, kent ve planlama anlayışında tüketim odaklı gösteri alanları haline gelen mekânlar üzerinden okunabilir. Bu durum, kapitalizmin yeni formlarla topluma, kültürlere yansıması ile de ilişkilendirilebilir (Akay, 2013 s.62). Postmodern kentleşme ve mimari biçim sorunsalında tüketme eylemi, ihtiyaç giderme eylemi olmaktan çıarak sosyal sınıfların kendilerini ifade etme biçimine dönüşmektedir. Pazarlamanın da metası haline gelen konut, kentlerde yaşanan dönüşümün en önemli göstergesi olarak kabul edilmektedir (Solak ve Oktay, 2017). Bu anlamda konut projelerindeki dönüşümler, toplumsal ve kültürel değişimlerin birer göstergesi haline gelmiştir. Kentten yalıtılan ve yeni yer kimliği ile kurgulanan tema 
içerikleri kullanılmaya başlanılmıştır (Süer ve Sayar, 2002, s.63). Rasyonel tüketim yerine sembolik tüketim olarak ifade edilebilecek bu süreçte, medyanın "iyi bir yaşam", "ayrıcalıklı bir yaşam" sunma vaatleri Baudrillard (2019, s.27)'nin "Doğrudan daha doğru olan, orada olmadan orada olma olgusu, başka bir deyişle fantazidir. Kitle iletişiminin bize verdiği gerçeklik değil, gerçekliğin başdöndürücülüğü̈ür" söylemi ile örtüşmektedir. Bu dönüşümler kent olgusu üzerinde tüketiciyi; sosyo-psikolojik bağlamda etkileyen, güdüleyen hedonist bir yapıya dönüştürmüştür.

Yeni bir mekânsal örgütlenme biçimi olarak ortaya çkan metropolleşme, tüketim mekânlarını yeni kentsel alanlar olarak karşımıza çıkarır (Yırtıcı, 2002). Projelerde düşsel imajların tatmin edilmesi amaçlanarak dünyanın çeşitli coğrafyalarından alınmış kent mekânları, simge yapılar, kentsel simulasyon örnekleri kullanılmaktadır (Süer ve Sayar, 2002). Bu yerleşik düzen içerisinde yer alan çoklu konutlar; coğrafi sınırların yok olduğu, dolayısı ile bağlamından kopuk, 'simulark' yaşamı kapsayan göstergeler ve imajlar bütünü olarak kurgulanır. Mimarın dekor olarak kurguladığı mekânlar; belli bir kültürü, imgeleri, zamanı yaşatan, tanınan mekânlardır (Süer ve Sayar, 2002). Kentten bağlamı koparılmış, çevresi ile iletişim kurmayan mekânlar, görsellik ve gösteri unsurlarının fazlaca yer aldığı birer alana evrilmektedir (Batı, 2008).

\section{Mimarlik ve Tüketim}

Mimarlık zaman, bağlam, kültür, sanat, etik gibi bileşenleri ve temelinde yakından bağlantılı olduğu insan, insanın beklentilerini tanımlama ve sınırlama gibi kaygıları içermektedir. Mimarlığın varlığı, insan ve onun gereksinimleri ile ilişkilidir (Soygeniş, 2017). Modernizmden sonra ortaya çıkan postmodernizm her alanda etkisini gösterdiği gibi, mekân ve yapı tasarımlarında da değişen yaşam standartları ile farklı bir felsefe arayışına girmiştir. Özellikle son yıllarda kentlerde hızlı bir değişimin yaşanması ile bu değişimin kentte var olan kimlik öğelerinin yitirilmesine neden olduğu gözlemlenmektedir (Oktay, 2011). Son 20 yılda kentlerin medyatik tüketim kültürüne teslim olarak imgesel düzeyde sosyal kodlar üzerinden tartışıldığı görülmektedir (Taşar, 2008). Küreselleşmenin siyasi, ekonomik, sosyal, vb. alanlardaki yansımalarl; küresel kent kavramı ile kendini göstermiştir. Bauman (2018), küreselleşmeyi son zamanlarda ortaya çıkan moda bir kavram olarak değerlendirirken aynı zamanda kontrol edilemez, ele avuca sığmayan, belirsiz, rahatsız edici bir his olarak nitelendirmiştir (s.75). Küreselleşme ile kentlerdeki 
değişim ve dönüşümün hız kazanmasında "küresel şehir", "dünya şehri" gibi kavramlar da ortaya çıkmaktadır (Bedirhan, 2016).

Tüketim ise birçok disiplinin ilgi alanına giren çok boyutlu bir kavramdır. Bugün tüketim, kapitalist toplumlarda önemli bir yer tutan yeni gündelik yaşam pratiklerini tanımlamaktadır (Batı, 2019). Küreselleşmenin hız kazanması ile tüketim kültürü; tüketiciye yenilik, toplumun geri kalanından ayrışma ve statü kazanma olanağı sağlamaktadır. Birey, tüketim kültürünün öznesi olurken tüketim kültürüne göre hareket eden, tükettikçe doymayan, kendisine sunulan her şeyi elde etmeye çalışan, etrafına yabancılaşan, salt kendisini düşünen bir varlık haline gelmiştir (Bedirhan, 2016).

Küreselleşen dünyada kapitalizmle birlikte kentleşme de boyut değiştirmektedir. Postmodernizm çağın ruhu ve teknolojik gelişimler doğrultusunda otoritenin etkili araçlarından biri olan "medya" ile kolay dönüştürülebilen, yönetilen, kontrol edilebilen bir toplum yapısı kurgulamaktadır (Karapınar, 2017). Bu noktada tüketimi tetikleyici yeni mekân anlayışlarının ve tüketim kültürünün hazza dayalı yeni yaşam biçimlerinin bireyi etkisi altına aldığ görülür (Batı, 2018, s.96). Konut pazarlama stratejileri ile bireylerin kullandıkları, harcadıkları, sahip oldukları "şeyler" üzerinden bireysel ve sosyal kimlikler inşa edilmekte ve üretilen konutların birer güç sembolü olarak tüketilmesi sağlanmaktadır (Kılıç ve Ayataç, 2019). Postmodern dönemde tüketime yapılan yönlendirmelerin en belirgin özelliklerinden biri de medyanın kitle iletişim araçları üzerinden kullandığı imaj ve göstergelerdir. Kullanılan göstergeler, tanıtımı yapılanın kullanım değerinden daha fazla dikkate alınmasina neden olmaktadır (Özcan, 2007). Medya ve reklam dili ile kullanılan kodlar ve simgeler, toplumsal alışkanlıkları değiştirme potansiyelleri yüksek ögeler olarak nitelendirilebilir. Kullanılan bu yöntemler ile "algı yönlendirmesi" yapılarak toplum belleğinde farklı olgular oluşturulmaktadır. Medyanın göstergeler, kodlar ve simgeler ile kurguladığı yeni yaşam biçimleri, kitleleri gerçek ile hayal olanı birbirinden ayırt edemez hale getirmektedir.

Kapitalist yaklaşımların tetiklediği tüketim toplumu olgusu, mimarlık pratiğinde "hedonik tüketim" kavramı ile ilişkilenmektedir. Mekân bu noktada bir tüketim nesnesine dönüşmektedir. "Postmodern dönemin modern dönemden önemli farklllklarmdan biri, tüketim ve tüketicinin konumudur. Modern dönemde tüketici, tüketim nesnelerini kontrol eden özne konumundadır. Postmodern dönemde ise, sonsuz pazarlama imajlarnyla tüketici, tüketilen konumdadır" (Barthes, 1999). Postmodern tüketim kültürü ile ortaya çıan kavramlar ve görsel ifadelerin yeni yaşam biçimleri üzerindeki etkileşimleri de bu yönde önem kazanmaktadır. 


\section{Postmodernite Kavramı ve Yaşam}

Postmodernizm ilk olarak 1960'lı yılların sonunda sanatta ve mimarlıkta yeni eğilimleri ifade etmek amacı ile ABD'de tartışılmaya başlanmıştır ve 1970'li yıllarda Avrupa' da çok parçalı dinamiklerin, arayışların, isyanların ve yeniliklerin stratejisi olarak görülmüştür. 1970 yılı öncesinde kavramın mimari ve sanatsal hareketleri anlatmak için kullanıldığı bilinmektedir (Özoran, 2019). 1970 'li ve 1980 'li yıllarda postmodernizm pek çok alanda popülerlik kazanmıştır (Odabaşı, 2017). Modernizm sonrası veya ötesi olarak tanımlanan postmodernizmin kavramsal olarak birçok alan üzerinde etkisi olduğu söylenebilir. Postmodernizm, Türkiye'de ise "megapoller" dönemi olarak da adlandırılan 1990'lı yılların başında gündeme gelmiştir (Akay 2013, s.7). Yaşanan I. Dünya Savaşı'nın ardından yıkımın düzeleceğine ve tekrar kurulacağına inanan insanlar, II. Dünya Savaşı ile umutlarını kaybederek gelecek endişesi ile "şimdiyi" yaşamayı tercih etmiştir ve kimi kesimler tarafından bu durum postmodernite enformatiğinin ortaya çıkış nedeni olarak kabul edilmiştir (Babacan ve Onat, 2002). Minoru Yamasaki tarafından tasarlanan ve St. Louis Missouri'de bulunan toplu konut bloklarının aşırı yoksulluk, suç oranlarında artış ve ırkçılığın ciddi boyutlara varması gerekçesi ile dinamitlerle havaya uçurulması "modern mimarlı̆̆ı öldügü gün" ve postmoderniteye geçişin sembolik tarihi olarak kabul edilir (Harvey 2019, s.54).

Postmodernizmin başlangıcı ile tüketim kültürünün oluşturduğu tüketim toplumu da bu sürecin bir uzantısı olarak görülebilir. Dönemselleşme olgusu içerisinde endüstriyelleşmenin bir ürünü olan kentleşme ile yaşam tarzında radikal ve hızlı değişimler ortaya çıkmaktadır. Modernite üretim ve çalışma ile tanımlanırken postmodern dönemde üretimden ziyade tüketim temel bir unsur olarak toplumda yer alır. Tüketim kültürü içerisindeki kent nosyonları ile kurgulanan simge yapılar ve mekânsal olarak birbirlerine entegre olmuş dünyalar, tüketicileri tüketmeye sevk eden birer temsil haline gelmiştir (Süer ve Sayar, 2002).

Postmodern toplumda hedonist bir yapiya dönüşen birey ise içerikten ziyade göstergeye ilgi duyan, isteğinin hemen gerçekleştirilmesini isteyen, anlık sevinçler ile günlük mutlulukların peşinde ve hazcı yanı ön plana çıkan bir özne haline gelmiştir (Odabaşı, 2017). Postmodernizm evresinde parçalanmış yaşam biçimleri ailelerin günlük yaşam deneyimlerine de etki eder. Örneğin her aile bireyinin farklı televizyon programını izleme isteği ve kendine ait odada "alan yaratma" beklentisi doğrultusunda oluşturulan mekânsal kurgular ile tüketiciye farklı bir yaşam senaryosu sunulmaktadır. 
Artık gelecek için tasarruf yapmak yerine tüketen, elindekilerle yetinmeyen, sürekli bir arayış içerisinde olan ve çalışmaktansa boş zamanını hedonist tüketim çemberi içerisinde geçiren topluluklar oluşmaktadır. Bu çember içerisinde tatmin olamayan birey, yeni arayışlara girerek döngüsünü devam ettirmektedir (Özcan, 2007). Tüketime dayalı hayat tarzı tercihleri bireyler arasında sınıfsal ayırımlar oluşturmaktadır. Böylelikle bireyin kendisini konumlandırdığı yerin topluma gösterilmesine dayalı bir sistem kurgulanmaktadır. Bu yaklaşım postmodern kent nosyonun işlev dışı örgütlenmesi ile kendisini mimari bir üslup olarak gösterir.

\section{Reklam Sloganlarn ve Vaatleri}

Günümüzde kentlerin ve mekânların tecimselleştirildiği, kentin tüketim eylemlerine göre tasarlandığı, gündelik yaşam etkinliklerinin yine tüketim davranışları üzerinden denetlendiği ve rasyonel bir zihin ile kurgulandığ 1 akıldışı bir sistem söz konusudur (Batı, 2008). Çok sayıda görüntü ve iletilerle çevrilmiş olan toplum, reklamlar aracılı̆̆ı ile yönlendirilmektedir. Bu yönlendirmeyi sağlayan medya, bireylerin yaşamdan memnuniyetsizlik ve eksiklik duyumlarını ortaya çıkarak reklamın amacına ulaşmasında önemli bir katalizör görevi görmektedir (Berger 2019, s.142). Bu bağlamda, bireylere sunulan farklı yaşam senaryosu anlatımlarına birçok konut proje reklamında rastlanmaktadır. Bir diğer anlamda, reklamlar ile toplumun üzerinde uzlaştığı değerler skalası oluşturulmaktadır (Güleç, 2019). Konuta yönelik gerçekleştirilen reklamlarda asıl hedeflenen tüketicinin gördüğü resim ya da fotoğraftaki yaşam tarzının satın alınabilir olduğu hissiyatını vermektir (Taşar, 2008). Yeni yaşam tarzına dair bir toplumsal statü belirlenirken gerçeküstü görseller, sloganlar, manipüle edilen reklamlar aracılığı ile konut artık bir tüketim metası haline getirilmektedir (Şahin ve Şener, 2018). Küreselleşmenin getirdiği tektipleşme, dünyanın küçülmesi ve tek tip yer olarak algılanmasına neden olur. Reklamlar, bu noktada bir katalizör görevi görerek tüketim kültürünün sihirli bir değneği olarak kullanılmaktadır. Medyada yer alan ve asıl hakikati gizleyen simülasyonlarla dolu lüks konut reklamları, bu yönlendirmenin somut göstergeleridir (Bedirhan, 2016).

Kent olgusunda yaşanan değişimler, postmodernizm arayışının ve ifadesinin bir sonucudur. Kalabalıktan ayrılarak farklılaşmak isteyen birey, yaşadığı mekânlarda da kendi kimliğini sorgulamaya başlamaktadır. Söz konusu yeni oluşumlar ile "ötekileri" dışlayan, kendi okulları, hastaneleri, sosyal kulüpleri olan ve kentin birer alt kümesi haline gelen mini kentler oluşturulmuştur (Batı, 2008). "Ayrıcalıklar merkezi" oluşturmak amacı ile konut 
üretimi yapan firmalar için "konsept" konutun kendisinden daha önemli hale gelmiştir. Kentte çevresel ilişkilerden kopuk olan ve bir boşluğa konumlandırılan yaşam alanları, medyanın reklamlar aracıllğı ile yarattığı soyut tasvirleridir (Gön, 2017). Kitleleri manipüle eden bir olgu olarak her gün karşılaştı̆̆ımız reklamlar, toplumsal algıyı yönlendirmekte ve belleğin yarattı̆ 1 anlam ve beğenilerin bu şekilde değişmesine neden olmaktadır (Şahin ve Şener, 2018). "Konsept" gösterişli tüketim kültürü kavramı ile "ne kadar farklı, o kadar pahalı"; konut kullanıcısı için ise "ne kadar farklı, o kadar prestijli" algısı ile sisteme empoze edilir (Kılıç ve Ayataç, 2019). Mekânın artık ihtiyaç ve kullanım değeri göz ardı edilerek prestij, imaj ve gösterge değerleri dikkate alınır.

Gündelik yaşamın estetikleştirilmesi ile postmodern kent mimarisinin tema ve kurgusal ayrışma neticesinde oluşturduğu kent metaforları ve imgeleri, kent kültürünü yan anlamlara dönüştürmektedir (Batı, 2008). Susan Buck-Morss (1992) modern dünyaya karşı geliştirilen savunmaların hayali görünüşlerin belirli temalara göre düzenlenmiş panoramalar olduğunu ifade eder. Sanal gerçeklik, içinde bulunulan toplumsal yapının politik ve kültürel gerçeklerinden biridir ancak oluşan sanal imaj, aynı zamanda gündelik hayattaki bir yanılsama olarak karşımıza çıkar (Robins, 2013). Postmodern tüketim kültürünün sonuçlarının görünenin ötesinde aranması gerektiğini vurgulayan David Harvey, bu arayışı insanlık parametrelerinde oluşan çok yönlü dönüşümlerle özetler (Bauman, 2018, s.8). Bu doğrultuda reklamları, tüketicinin deneyimlemek istediği ya da isteyeceği mekân kurgularını tasvir eden ögeler olarak tanımlamak mümkündür.

Kapitalizmin tüketim kültürü ile beraberinde getirdiği meta üretimi ve satın almaya odaklı düzen, yeni alışkanlıkları ortaya koyarak sınıfsal ayırımları gündeme getirmektedir (Aras, 2014). Günümüzde statü seviyesini belirleyen en temel unsur, sahip olunan göstergeler üzerinden tüketim kalıplarıdır (Perouse ve Danış, 2005). Pazarlama yöntemleri ile barınma kavramı değiştirilerek mekânın imaj odaklı değerini arttıran konut modası yaratılmaktadır (Şahin ve Şener, 2018). Pazarlama ve tüketiciye etkili ulaşmada bu noktalara vurgular yapılarak yeni yaşam biçimlerinin sınırları sözel ve imgesel olarak çizilmektedir. Seçkinlik ve ayrıcalıklı olma kavramları, reklam ve tanıtımlarda; prestijin anahtarı olarak sunularak önemli bir pazarlama stratejisi haline gelmiştir. Amaç, kimliğin yeniden üretilmesidir ve sınıfsal göstergelere yönlendirilen tercihler ve olanakların hazır bir paket halinde tüketiciye sunulmasıdır. Günümüzde konutun da bir statü göstergesi olarak kabul edilmesiyle belirli bir tema ve konsept ile marka oluşturulmaktadır. Bu noktada 
reklam sloganları, projenin ve hedef kitlenin kriterlerine göre belirlenmektedir. Tüketicinin seçilen sloganlar ile dikkati çekilerek doğru reklam konumlandırmaları ile projeye ilgileri sağlanmaktadır. Projelerde sıklıkla kullanılan sloganlarda doğa, manzara, kentsel kimlik, yenilik, prestij, statü, yeni yaşam ve komşuluk gibi kavramlara rastlanmaktadır. Bu kavramlar mekânsal kimlik, sosyo-kültürel kimlik, kentsel kimlik ve küresel kimlik ile pazarlanan projelerde yer alan pazarlamanın hedef kitleye ulaşmasındaki önemli ayıraçlarıdır (Kılıç ve Ayataç, 2019).

Kentin farklı bölgelerinde kurulan ve genellikle simülasyon ile retro tarzı ya da atmosfer ile metropolü taklit eden proje tanıtımlarında özlem duygusu işlenmektedir ve tüketicinin zihninde farklı temsiller yaratılmaktadır. Simülasyon mekânlar olarak da adlandırılan bu mekânlar, postmodern bir yaklaşımla bir şehre, ülkeye referans veren yaşam kurgularıdır (Kılıç ve Ayataç, 2019). Dünyanın farklı coğrafyalarından alınmış kentsel mimari öğeler, insanda "hiçbir yerde ama her yerde olma" hissi uyandırmaktadır (Süer ve Sayar, 2002). Kurgulanan bu yaşam alanlarında taklide dayalı mekânsal ögeler tasarlanarak sunulan yeni yaşama dair imajlar oluşturulmaktadır.

\section{Yeni Yaşamlar ve Göstergeleri}

\section{Örnek Projeler Üzerinden Yeni Yaşam Göstergelerinin Analizi}

Her mekân bir yaşam biçimini yansitır. Postmodernizm de yeni bir yaşam biçimi tanımlayarak bireylerin özel zevklerine yönlenen bir yaklaşım olarak mimariye yansır. Postmodernitede mekân, tarzların iç içe geçtiği, estetiğin öncelikli tutulduğu değişken bir biçimdir. Toplumsal örüntülerin sürekli değişimi doğrultusunda oluşan yeni yaşam biçimleri ve tüketim kültürleri ile öznelleşmiş bir mimari tarzdan söz etmek mümkündür (Batı, 2008). Baudrillard (2018)'in simülasyon kavramı düşünüldügünde, hakikat ve gerçeklik kavramlarının önemini yitirdiği ve asıl gerçekliğini yitirmiş göstergeler üzerinden yaşamların kurgulandığı tanımlanabilir. Üzerine konsept giydirilmiş olarak sunulan yaşamlar, aslında bireyin şimdiye kadar arzu ettiği gerçeklikler olarak yansitılır (Çinçin, 2018). Günümüzde kurgulanan yaşam alanlar1nın kent nosyonundan uzaklaşması ile oluşan yersizlik ve kimliksiz kavramları da proje sınır(lılık)ları dahilinde ortaya çımaktadır.

Tanımlanan problem ve kavramsal çerçeve doğrultusunda, araştırmanın yöntemi iki aşamalı bir kurguda tasarlanmaktadır. Birinci aşamada, tema içeriği olan projelerin tema ve sloganları incelenerek seçilen postmodernite kavramları üzerinden gösterge-kavram eşleştirmesi yapılmaktadır. İkinci aşa- 
mada ise elde edilen eşleştirmeler sonucunda gösterge-kavram ilişkileri incelenmektedir. Bu noktada, seçilen projelerdeki reklam sloganları, postmodernite kavramları ve temalar üzerinden ele alınmaktadır. Harvey ve Baudrillard'ın kuramları üzerinden "yeni yaşam göstergeleri" çerçevesinde mekânsal ve toplumsal kimliklerin oluşumu hakkında bir değerlendirme yapılmaktadır.

\section{Örnek Seçim Kriterleri ve Analiz Yöntemi}

Çalışmada tüketim unsuru doğrultusunda evrilen konut anlayışının kent yaşamındaki göstergeleri irdelenmektedir. Konut reklamları ile tüketiciye sunulan hayat tarzları, reklam metinlerinde vaat edilen yaşam modelleri, sunulan imgeler ve yaratılan mitlere ilişkin literatür taraması yapılarak ilişkili kaynaklar incelenmiştir. Çalışmanın konusu itibari ile farklı disiplinlerden bilgi aktarımı ile özellikle toplum felsefesi ve iletişim disiplini içerisindeki medya bölümünden bilgi aktarımına ihtiyaç duyulmuştur. Konut reklam incelemelerinden farklı olarak, D.Harvey ve J.Baudrillard'ın kuramları ile kent, konut ve yaşam modelleri üzerine çıkarımlar sağlamak amaçlanmıştır. Postmodern tüketim kültürünün etkisi ile hızlı bir değişim sürecine giren kentlere bakıldığında; Türkiye özelinde bu sürecin gerçekleştiği önemli metropollerden birinin İstanbul olması gerekçesiyle örneklem bu kent özelinde sınırlandırılmıştır. Bu kapsamda, İstanbul'da gerçekleşen kapalı konut sitelerinin tanıtımları incelenerek temalı konut içeriğine sahip 10 adet proje örneklem olarak seçilmiştir. Çalışmanın konusu olan ve son zamanlarda popülerleşen temalı konut projelerinin proje metinlere dair okumalar yapılmıştır. Yapılan okumalar doğrultusunda "söylem analizi" yöntemi kullanılarak projelerde sıkça yer verilen sloganların tekrarlama sıklıklarına bakılmış ve bu kavramların ilişkileri örnekler özelinde analiz edilmiştir.

Belirlenen kriterler doğrultusunda projelerde yer alan reklam afişleri, görselleri, metinleri ve tanıtım filmleri "postmodernite" kavramları ile ilişkilenecek şekilde "proje tanıtım sloganları" başlı̆̆ı altında sıralanarak sonuçlar ortaya konulmuştur (Şekil. 1-2). Araştırma özelinde seçilen örnek projelerdeki yeni yaşam göstergelerinin analizleri yapılarak bu göstergelerin mimari üsluptaki yansımalarının kullanılan reklam dili üzerinden okunması amaçlanmiştrr. 


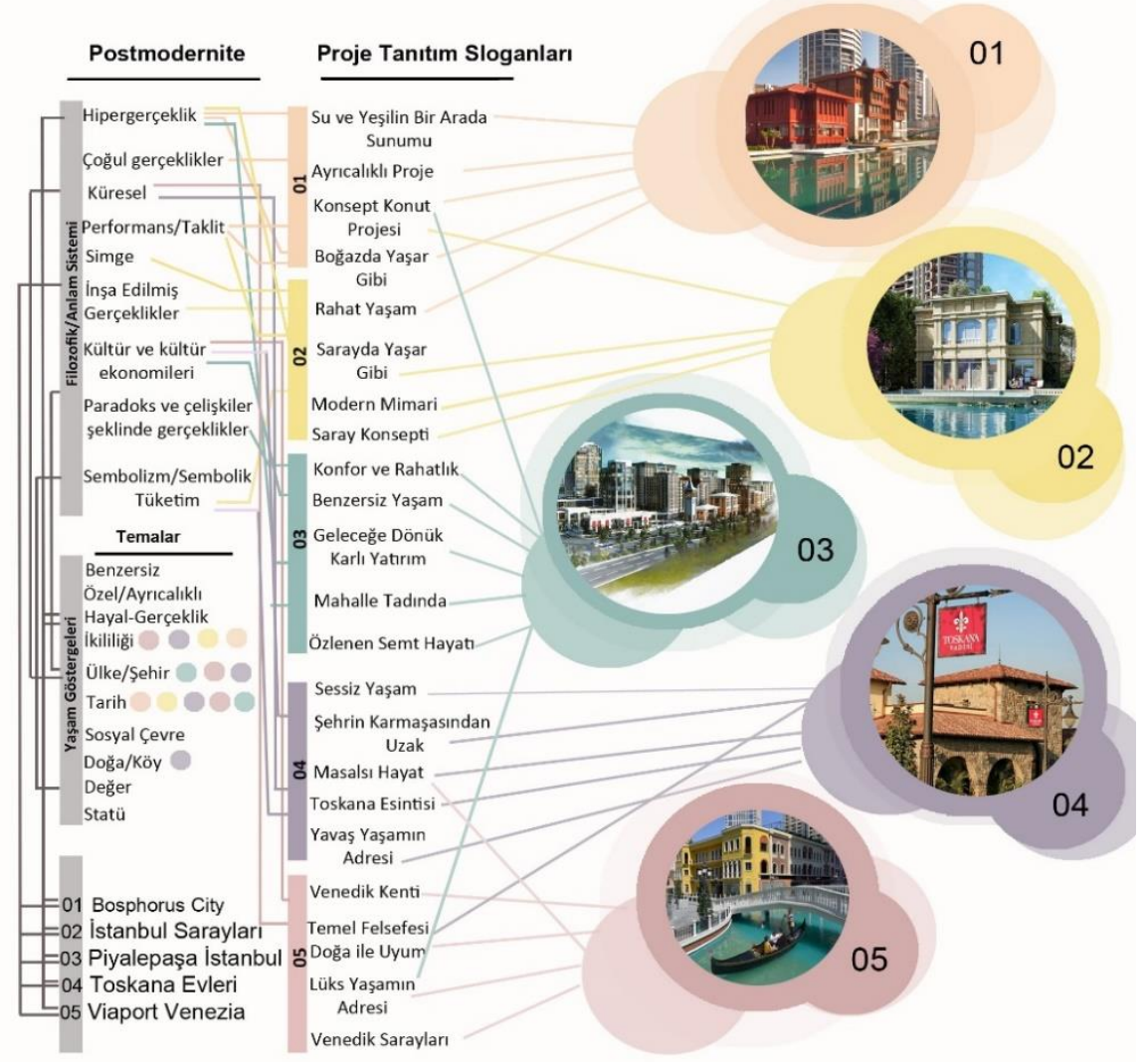

Şekil 1. Temalı Konut Projeleri Kavram/Tema/Proje Sloganı Analizi. Proje örneklem dizisi 01-05. (Yazar tarafından oluşturuldu) 


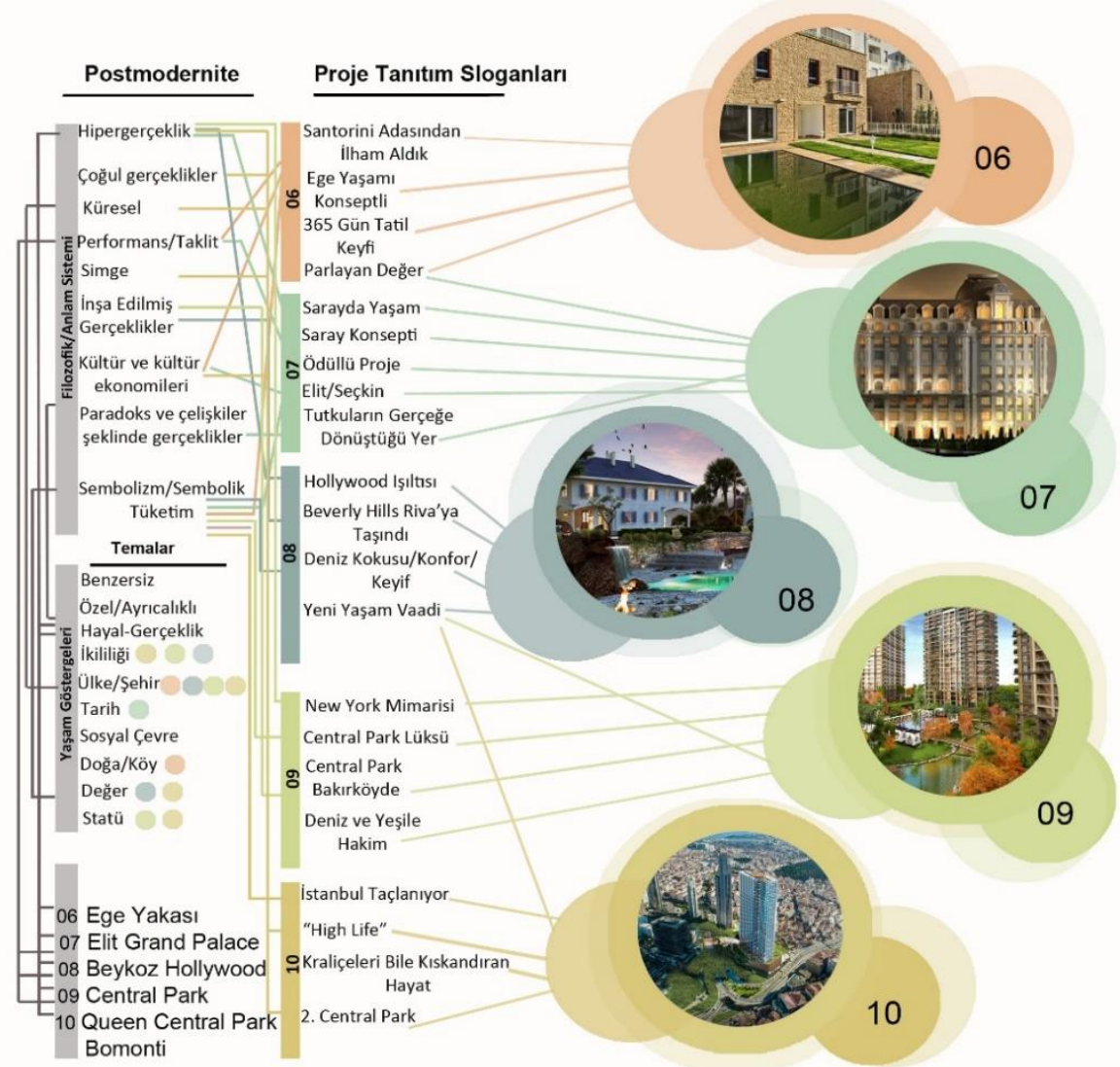

Şekil 2. Temalı Konut Projeleri Kavram/Tema/Proje Sloganı Analizi. Proje örneklem dizisi 06-10. (Yazar tarafından oluşturuldu)

Bu kapsamda analiz edilen projelere ilişkin kavramlar/temalar ve proje sloganları ilişkisine bakıldığında, kent bağlamından kopuk bir örgütlenmenin söz konusu olduğu söylenebilir. Tüketiciye sunulan tanıtıma dayalı proje sloganları doğrultusunda tanımlanan ihtiyaçlar, imaj ve göstergeler üzerinden insanların kendini ifade etme biçimi olarak mekânsal kurguya eklemlendirilmektedir (Şekil 1-2).

\section{Örnek Analizleri}

Bosphorus City İstanbul Konut Projesi: Seçilen temalı konut projelerinin proje sloganları üzerinden analizini içeren ilk örnek proje, İstanbul Bosphorus City Projesi'dir. Projenin seçilme nedeni, kentin sahip olduğu mekânsal ve tarihsel kimliği oluşturan ögelerin projede gösterilme çabasıdır (Şekil 3). Bosphorus ismi ile, kentin kimliği arka plana atılarak şehrin sloganına dair 
mekânsal bir kimlik oluşturulmuştur. Proje'nin tanitım filminde (Mood Production, 2016a); Boğazın kardeşi, Bosphorus City. Boğazın tüm güzellikleri yeniden birer birer inşa edildi. Ortaköy'ü satışa sunuyoruz. Boğazm misafiri değil, ev sahibi olmanız için. Yeni bir coğrafya, 2. İstanbul Boğazı sloganları ile İstanbul Boğazı'nda yüzen sporcunun, tanitım filmi sonunda aslında projede oluşturulan boğazda yüzdüğü anlaşılır. Aradaki farkın anlaşılamayacağı bu yöntem ile anlatılmış olur.

Firmanın proje tanıtım metninde (Sinpaş GYO, 2019a);

Projede mimari tasarımdaki en önemli girdi, zengin açık alan kullanımı sağlayan su ve yeşilin bir arada sunulduğu rekreasyon alanlarıdır. Arazinin uzun yapısına uygun olarak konumlandırılan su, alanı iki ayrı yakaya bölerek birbirlerine geçişlerle dinamik bir kentsel ağ örüntüsü oluşmasını sağlar (...) Konut çözümlerinde de benzer bir anlayış hakimdir; geleneksel sivil mimarinin özellikli örnekleri plan ve cephe düzleminde modernize edilerek projeye özgün bir nitelik kazandırır ifadelerine yer verilmektedir.
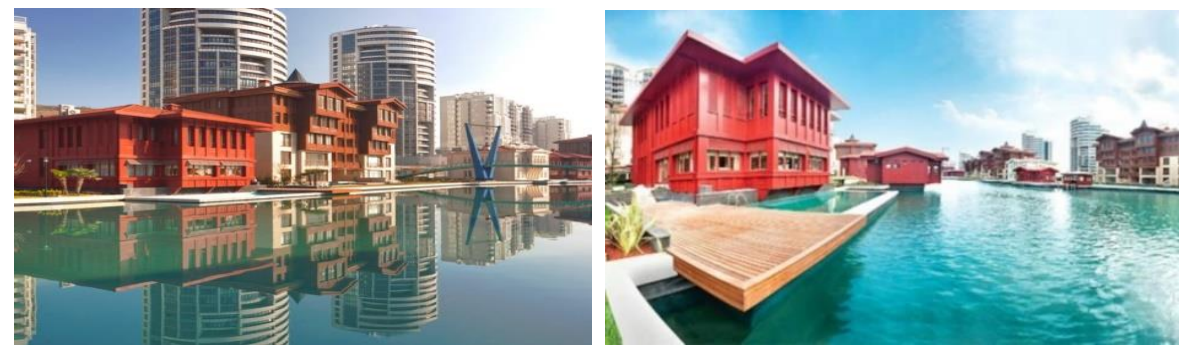

Şekil 3. 01- Bosphorus City İstanbul Konut Projesi Görselleri, Yapım Yılı: 2008-2012 (Sinpaş GYO, 2019a).

İstanbul Sarayları, İstanbul Konut Projesi: Proje, İstanbul Halkalı'da bir kentsel dönüşüm projesi olarak yer almaktadır ve İstanbul Bosphorus City Projesi'ne komşu parselde hayata geçirilmiştir. Sarayda yaşar gibi sloganı ile reklam tanitım filminde tüketiciye (Mood Production, 2016b);

Bugün saraylısın, uyandığında bütün dünya onunla beraber uyansın ister. $\mathrm{O}$ istese de sıradan olamaz. Bugünün saraylısı için gerçek zenginlik hayatın zevklerini çoğaltmaktan geçer. İstanbul sarayların, modern mimari ile yeniden yorumluyor. Bu yepyeni saraylar şehri; köşkler, yalılar, saray daireleri gibi çok seçenekli yaşamları ile yeni sultanlarını bekliyor şeklinde bir yaşam sunmaktadır (Şekil 4).

Proje açıklama metninde saraylardaki yaşamın rasyonalize edilmesiyle kent mekânlarının da birer tüketim unsuru olabileceği ifade edilmektedir. 
Firma proje tanıtım metninde (Sinpaş GYO, 2019b);

Suyun yarattı̆̆ doğal ortama, koşu ve yürüme yolu olarak kullanılan 2 adet promenat üzerindeki "Saraylar" konsepti ilkeleriyle tasarlanan yalı ve konaklarının bulunduğu korular eşlik eder. Suyun kenarında farklı tip konut önerileriyle yalılar, yalı apartmanları ve konaklar mevcuttur (...) Buluşma, karşlaşma, boş zaman değerlendirme gibi kullanıcılarına nitelikli bir sosyal bir ortam sunması için meydanlar önerilmiştir ki tüm meydanlara koru bölgelerinden yaya olarak ulaşmak mümkündür açıklamaları yer almaktadır.
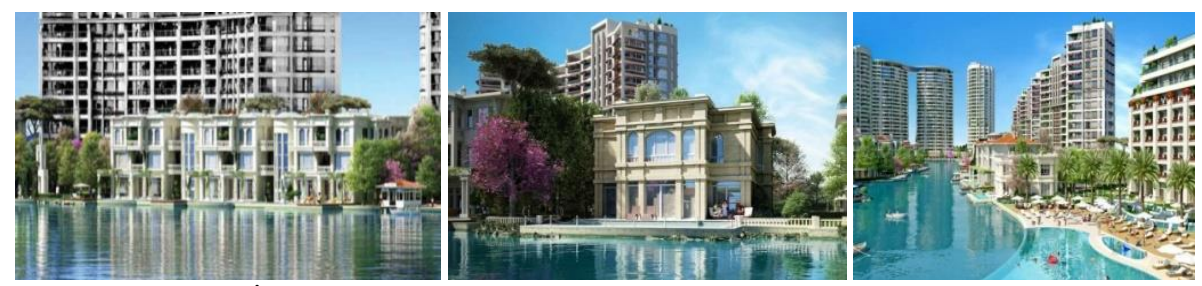

Şekil 4. 02-İstanbul Sarayları Konut Projesi Görselleri, Yapım Yılı: 2010-2013

(Sinpaş GYO, 2019b).

Piyalepaşa İstanbul Konut Projesi: İstanbul'da "Piyalepaşa İstanbul" ismi ile yer alan proje, “Bir Semti Yeniden İnşa Ediyoruz" slogan ile bölgenin tarihi geçmişi ve özlenen mahalle hayatını ön plana alarak yeni bir semt algısı oluşturmuştur. Proje tanıtımlarında İstanbul'un yaklaşık 500 yıllık tarihi geçmişine değinilerek Kaptan-1 Derya Piyale Mehmed Paşa tarafından kurulan semtin hak ettiği itibara kavuşturulacağından söz edilir ve "Piyalepaşa'ya iade-i itibar" sloganı ile tarihe özlem duyan kitleye seslenilir (Emlak Haberleri, 2015). Döneminin karakteristik mimari üsluplarından çok bölgeyi gündelik yaşam ve tüketim kavramları üzerinden örgütleyen projede tarihi öğelerin yan anlamlara dönüştürüldüğü görülmektedir.

Proje tanitım filminde kurgusal bir anlatım kullanılarak yere inen beton bloklar ve yakın çekim ile bir mahallenin kurulum simülasyonuna tanıklık edilir. Ortaya konulan hipergerçeklik ile şantiye ortamına vinçler ile simitçinin, mahalle manavının, ağaçların, mekânların yerleştirildiği tanıtımda proje şu ifadelerle tüketiciye sunulur: Efendim, telaşımızı mazur görün. Koca bir semt inşa etmek kolay değil. Biz burada İstanbul'un en eski semtlerinden birini, Piyalepaşa'y yeniden inşa ediyoruz. Hep özlemini duyduğunuz semt hayatı burada (Polat İnşaat, 2019). Tanıtımda şantiyede yer alan proje sorumlusunun ortaya koyduğu ifade, bir simülasyon örneği olarak tanımlanabilir. 

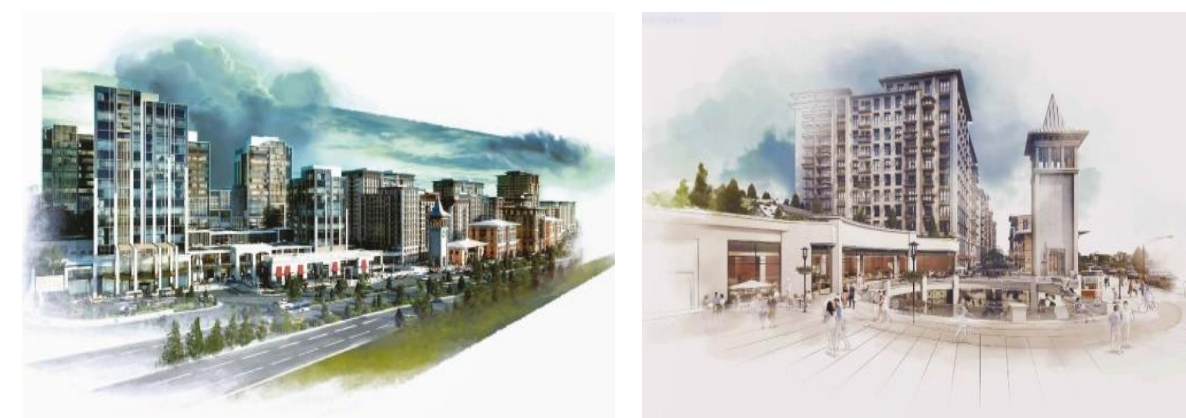

Şekil 5. 03-Piyalepaşa İstanbul Konut Projesi Görselleri, Yapım Yılı: 2015-2020

(Polat İnşaat, 2019).

Toskana Evleri Konut Projesi:İstanbul Büyükçekmece semtinde inşa edilen proje, İtalya'da bulunan Toskana Bölgesi'nin adını taşımaktadır (Şekil 6). Kentin karmaşasından uzaklaşma fikrinden yola çıkılarak diğer projelerle benzer satış stratejisi geliştirilen projede İtalyan mimarisi ön plana çıkarılmaktadır.

Proje tanitım filminde (Emlak Rotası, 2014);

Şehrin gürültüsü, ses ve hız ile karmaşadaki gerginlik ve stres sizce yaşam olabilir mi? Hayata tutunmak istiyorsanız acele etseniz iyi olur. Bu sizin elinizde... Akdenizli bir soluk ile beslenen masalsı bir hayat. Aradığınız huzuru, özlemini duyduğunuz doğallı̆̆ı, çiçeğin kokusu, suyun safllğın hayatınızın merkezine koyan yer. Doğa ile modern hayatın kaynaştı̆̆ı, kusursuz bir yaşam sunan Toskana Vadisi'nde, tek katlı villa yaşamı... Toskana'nın o eşsiz yaşam kültürü, yüzyıllarla beslenen mimari mozaiği, taşından dokusuna, tadından kültürüne, Toskana esintisi İstanbul'da. Yavaş yaşamın Türkiye'deki adresi. vurgusu yapılmaktadır.
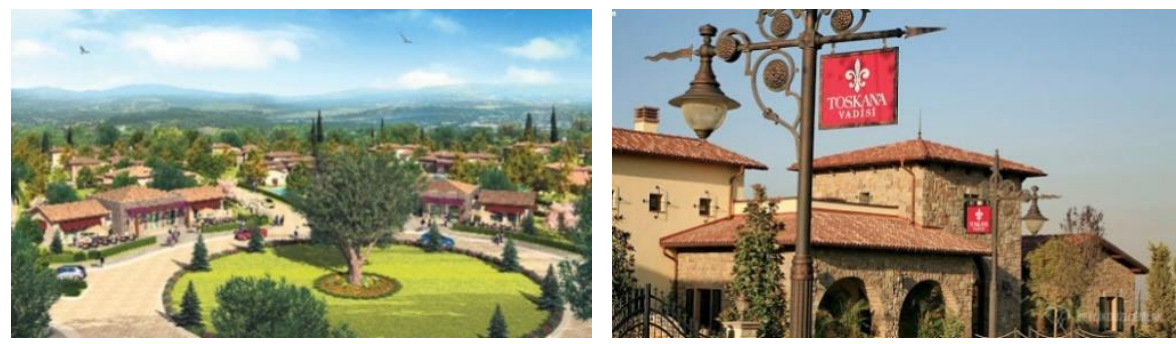

Şekil 6. 04-Toskana Evleri Konut Projesi Görselleri, Yapım Yılı: 2014-2018 (Emaar, 2016).

Via Port Venezia Konut Projesi: İtalya'nın Venedik kentinin mimari özellikleri ve kentsel etkinliklerinin de dahil edildiği projede simülasyon bir yaşam alanı ve yaşam tarzının ortaya çıkarıldığı görülmektedir. Proje; konut üniteleri, ofisler, mağazalar, rekreasyon ve spor tesislerinin bulunduğu 
karma kullanımlı bir biçimlenişe sahiptir (Şekil 7). Proje tanıtım filmi, İtalya'nın Venedik kentinde tatil yapan bir çiftin konuşması üzerinedir: Venedik'i çok sevdim, Venedik'te balayımı hiç bitmesin...Biz zaten Venedik'te yaşıyoruz. Bir metro ile annenlerdesin, tüm özel günlerde Venedik'teyiz. 4 gün 3 gece değil, tüm ömür Venedik (Proje Konutları, 2016).Proje:

İstanbul'un gelişen merkezi Gaziosmanpaşa'da konumlanmış olan Viaport Venezia, kanallarla çevrili düzenlemesiyle Venedik hissiyatı yaşatan kaliteli konut ve ofis ortamı sunmaktadır. Tasarımın binaya değer kattığını bilen, çevreye duyarlı yeşil yapılar yapmayı hedefleyen, temel felsefesi doğa ile uyumlu mekânlar yaratmak olan ofis, bu amacı gerçekleştirmek için sürdürülebilir tasarım ilkelerini tasarımın estetiği ile birleştirmeyi hedeflemektedir ifadeleriyle açıklamaktadır (Bayraktar İnşaat, 2015).
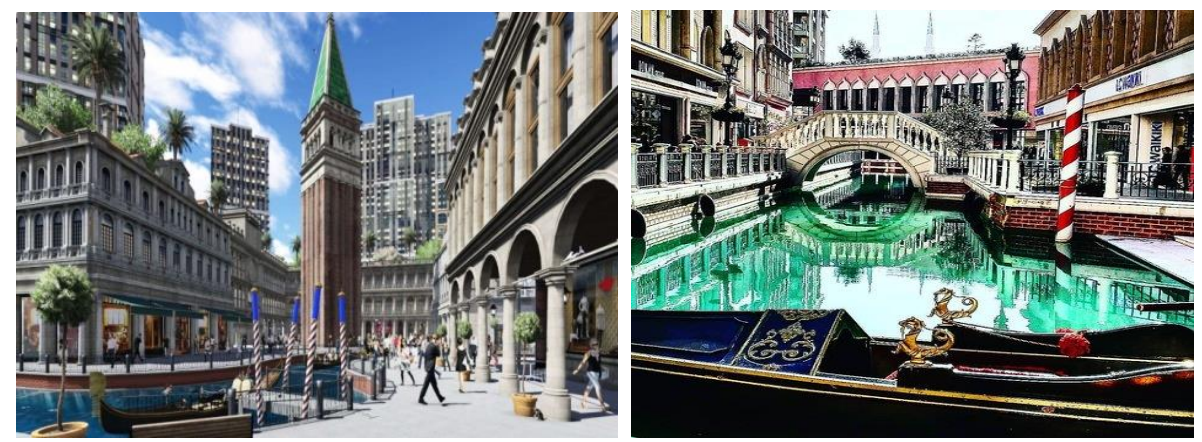

Şekil 7. 05- Via Port Venezia Konut Projesi Görselleri, Yapım Yılı: 2011-2016

(Bayraktar İnşaat, 2015).

Ege Yakası Projesi: İstanbul'da Ege teması ile ön plana çıan projede; Ege'nin tarihi mimari dokusu, topografyası ve iklimsel özellikleri görsel olarak bölgeden alıntılar yapılarak anlatılmaktadır. Ege'nin kendisine özgü mimarisi ve sahip olduğu kimlik öğeleri projeye yüklenerek tüketiciye "oradaymış gibi" bir yaşam tanımlanmaktadır. Ege aracılığı ile bir proje imgesi oluşturulmaktadır (Şekil 8). Tanıtım filminde Ege temaları kullanılarak (Yeni Projeler, 2014); Biz Ege'yi çok sevdik, Ege bize yakın olsun.... şarkısı uyarlanarak Ege yaşamı tüketiciye sunulmuştur.

Ege teması ile ön plana çıkan projenin Avrupa Yakası'nda en çok beğenilen ve en çok kazandıran Ege yaşamı konseptli konut projesi olduğundan söz edilmektedir:

Ege'yi rezidans konforu ile yaşayın" slogan ile proje açıklanmaktadır: İstanbul'un parlayan değeri, Halkalı Alkent'teki konut projeleri arasında cumbalı, panjurlu, taş dokulu evleri ve geniş balkonlarıyla dikkat çeken Ege Yakası, 
size 365 gün tatil keyfiyle yaşama mutluluğunu sunuyor. Sakız ve zeytin ağaçlarıyla Ege Yakası'nın kendinizi Ege'de hissetmenizi sağlayacak peyzajına hayran kalacaksınız. Alaçatı, Assos, Cunda ve Foça meydanları ile özlediğiniz Ege, artık hep yanı başınızda olacak" (Sinpaş GYO, 2019c).
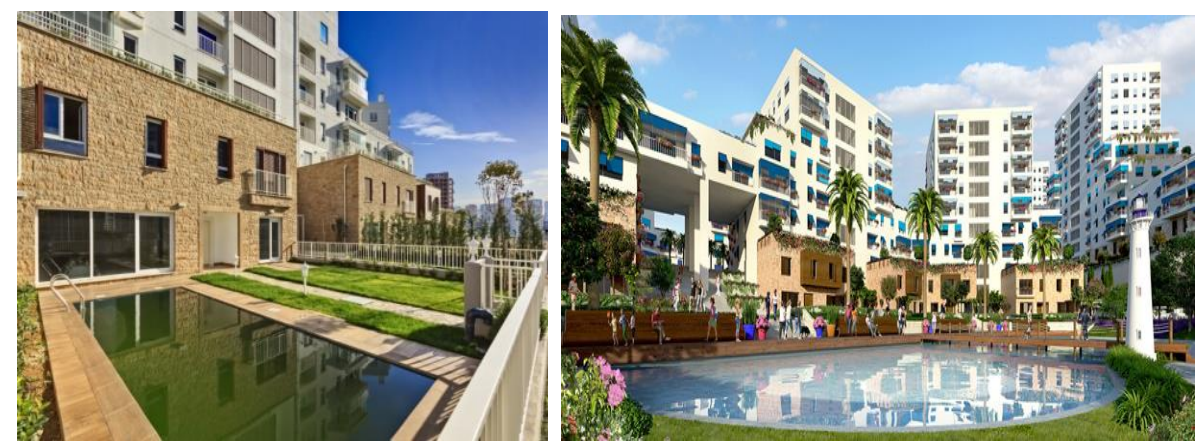

Şekil 8. 06-Ege Yakası Konut Projesi Görselleri, Yapım Yılı: 2014-2016 (Sinpaş GYO, 2019c).

Elite Grand Palace Konut Projesi: İstanbul Kurtköy'de yer alan projenin tanıtımı birçok tema ve kavram üzerinden yapılmaktadır (Şekil 9). Ödüllü proje olması; Selçuklu mimarisinden günümüze gelen Türk mimarisinin görkemli eserlerinden esinlenilmesi; Roma, Bizans ve Osmanlı medeniyetlerinden günümüze uzanan bir köprü olması gibi ifadeler proje tanıtım metinlerinde tüketiciye aktarılmaktadır.

Tanıtım filminde yer alan ifadeler şu şekildedir:

Bir tutkudur, görkemli saraylarda yaşama isteği. Ne zaman Dolmabahçe Sarayı'nı görsek, ne zaman bir fasıl çalınsa, ya da ne zaman Topkapı Sarayı'nın önünden geçsek, hep bir parçamızın oraya ait olduğunu hissederiz. Kendimizin bir parçasının saraylara ait olduğunu hissederiz, kendimizi o saraylarda yaşarken hayal ederiz. Biz bu tutkuyu gerçeğe dönüştürdük. Geçmişin görkemini, geleceğin yaşam tarzını, günümüz inşaat teknolojileri ile bir araya getiriyoruz. Tutkuları gerçeğe dönüştürmek için Selçuklu döneminden günümüze gelen klasik Türk mimarisinin görkemli eserlerinden ilham alınarak tasarlanan saray konforunda daireler... 208 metre cephesi ile saray yaşantısı sunan Elite Grand Palace. (Delmar Yapı, 2011). 


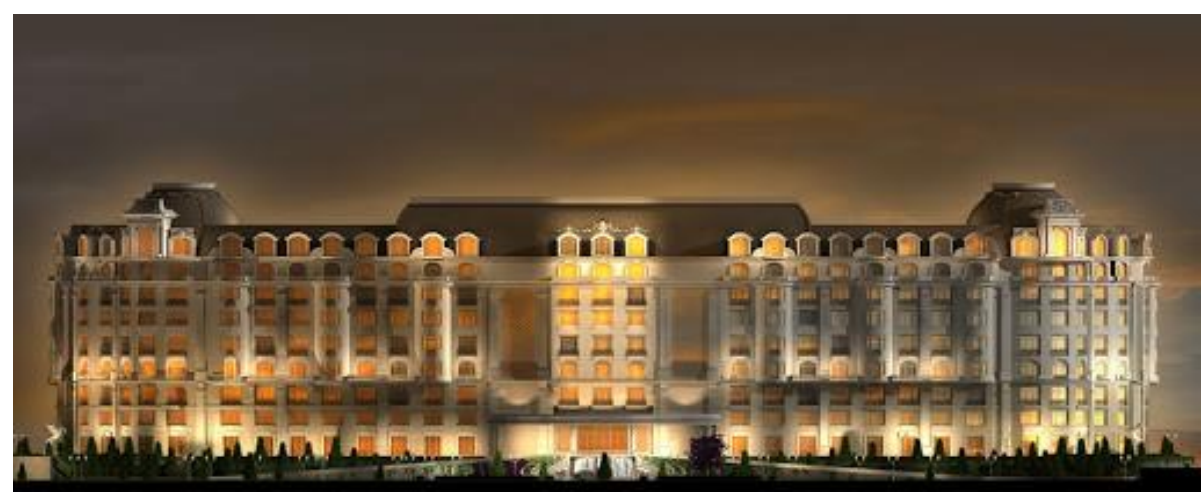

Şekil 9. 07- Elite Grand Palace Konut Projesi Görselleri, Yapım Yılı: 2011-2014 (Delmar, 2011).

Beykoz Hollywood Konut Projesi: İstanbul Riva'da bulunan proje Hollywood temalıdır (Şekil 10). Proje tema ve sloganlarında (Dost Beykoz, 2016);

Film tadında yaşanmak üzere tasarlandı, Beverly Hills Riva'ya taşındı... Riva Hills Projesi, geliştirilen villa konsepti ile Hollywood ışıltısını yansıtıyor. Palladyen ve Romanesk izler taşıyan villaları ile ormanın yanı başında, deniz kokulu, konfor ve keyfi bir arada barındıran yeni bir yaşam tarzı vaat ediyor. Hayatın özel anlarını film karesinde dönüştürmek için olağanüstü güzellikte mekânlardan oluşan Riva Hills'te havuz keyfi yaparken palmiyeler arasinda Hollywood pırıltısını hissedeceksiniz! ifadeleri yer almaktadır.

Tanıtım metinlerinde yine tüketicide hayranlık duyulan şehir yaşantısı ile "yanı başınıza getirdik" algısı oluşturulmaktadır. Tanıtım görsellerinde Beverly Hills görsellerini anımsatan birtakım öğeler ve figürler ön plana çıkarılmış, proje arka planda tutulmuştur. Projenin tüketiciye sunulma biçimi, söz konusu ögelerin ön plana çıkarılması kaygısını göstermektedir (Şekil. 10).

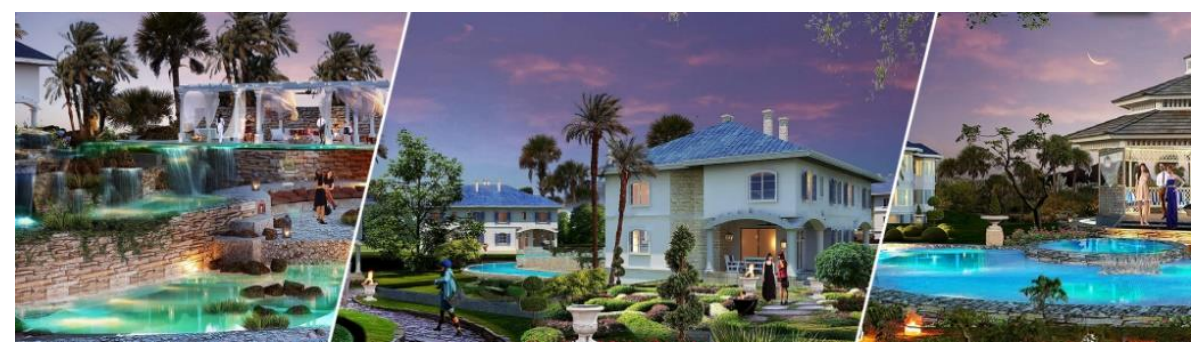

Şekil 10. 08- Beykoz Hollywood Konut Projesi Görselleri, Yapım Yllı: 2014-2016

(Eyfel Yapı, 2016). 
Central Park Projesi: İstanbul Bakırköy'de yer alan ve yapımı devam eden projenin teması, New York kentinin simgesi olan Central Park'tır (Şekil 11). Daha önce Bakırköy 46 adı ile satışa çıkan proje, isim değişikliği sonrası Central Park ismi ile tanıtımlarına devam etmiştir. Central Park Logo yarışması düzenleyen inşaat firması, bu etkinliği ile tanıtımını daha etkin kılmıştır. Firma sahibinin rol aldığı tanıtım filminde (Projede Firsat, 2017); Gittik, gördük, beğendik, New York Central Park'ın konforu ve lüksü şimdi İstanbul, Bakırköy'de. Yaptık oldu. Nokta. konuşması ile proje tanıtımı gerçekleştirilmiştir.

Bu noktada projede tanımlanan kent imgesi ile projenin yer alacağı kent imgesi arasındaki mekânsal kurgu ve gündelik yaşam pratiklerine dair örtüşme durumunun ne ölçüde sağlanabileceğinin sorgulanması önem kazanmaktadır.

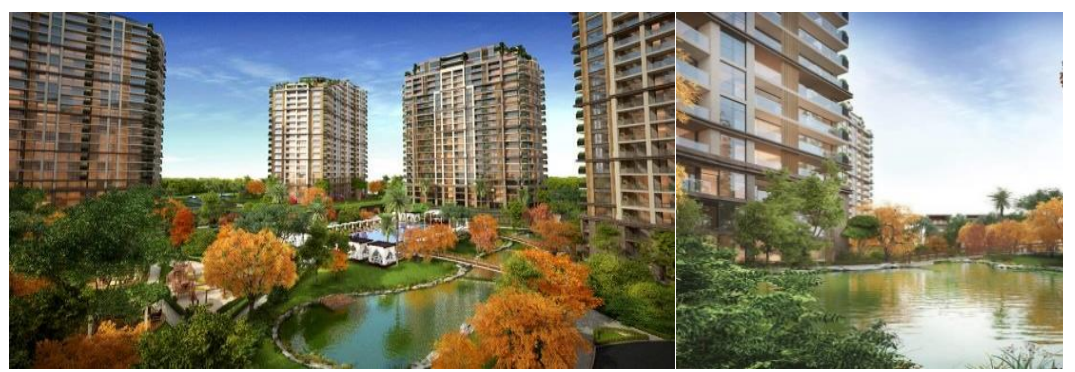

Şekil 11. 09-Central Park Konut Projesi Görselleri, Yapım Yılı: 2017-2020 (A ğaoglu İnşaat, 2017).

Queen Central Park Konut Projesi: İstanbul Bomonti'de yer alan projenin yapım firmasının 45. kuruluş yıldönümü kutlamaları ile birlikte tanıtımı gerçekleştirilmiştir. Proje geliştirme sürecinde İstanbul'un sembolik ve özgün mimari karakterinden yola çıkıldığı ifade edilen projede lüks yaşam teması vurgulanmaktadır. "Kraliçeleri bile kıskandıracak yaşam" sloganıyla dikkat çeken reklam filminin gösterildiği proje tanıtım toplantısında, New York'un kentsel kimliğindeki "Central Park" ve "İngiltere Kraliçesi" imgeleri ile projenin tanıtımı gerçekleştirilmiştir. Tema içeriğinde farklı imgeler kullanılarak yapı üzerinde konumlandırılan taç formu ile proje kentsel kimliğin bir parçası olarak değil, "simülakr" mekânlar üzerinden konumlandırılmıştır (Şekil 12). Tanıtım filmi İngiltere kraliçesi olarak rol alan kişinin konuşması üzerinedir:

Bugün aldığım bir haber ile derinden sarsıldım. İnanabiliyor musunuz? Central Park İstanbul'u hayata geçirmişler. Mimarisinde taç varmış. Bir de özel hizmetler koyup, adına da 'High Life' temalı evler demişler. Affedersiniz ama 'High Life' ne demek? Kraliçelere layık yaşam ne demek? Takdir edersiniz ki 
bunu en iyi ben bilirim. Central Park'ın bir benzeri yapılacak ise burada yapılmalıydı. Kraliçeniz olarak Queen Central Park'ın aynısını burada istiyorum. (Emlak Lobisi, 2020).
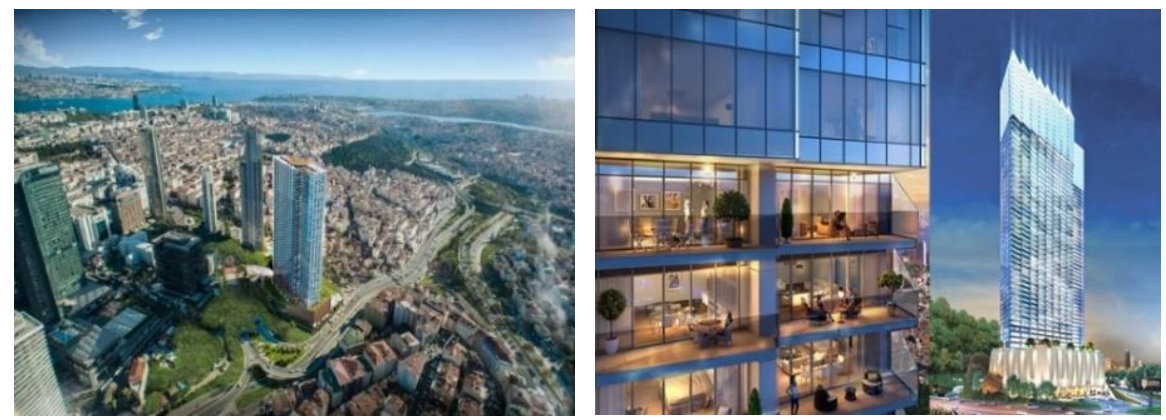

Şekil 12. 10-Bomonti Central Park Konut Projesi Görselleri, Yapım Yılı: 2015-2019 (Sinpaş GYO, 2016).

\section{Bulgular ve Değerlendirme}

Seçilen örnek konut projeleri üzerinden yapılan tema ve proje sloganları analizlerinde yoğunlaşan kavramlar; ülke/şehir, tarih ve hayal gerçeklik ikililiği temalarının etkileştiği bir çerçeve oluştururken değer, statü, doğa/köy, sosyal çevre ve benzersiz temaları sıklıkla projelerde yer alan ifadeler olarak karşımıza çıkmaktadır. Postmodernitenin filozofik/anlam karşılıkları çoğunluk olarak; hipergerçeklik, küresel, performans, taklit, simge, inşa edilmiş gerçeklikler, kültür ve kültür ekonomileri, paradoks ve çelişkiler, sembolizm ve sembolik tüketim alanları üzerinden kurgulanmaktadır.

Projelerde ülke/şehir imajlarının temsilleri, medya imajları ile vurgulanmaktadır. Ülke/şehir imajlarını içeren temsil biçimi, projelerdeki karşılığını tematik modelleme anlayışı ile bulmaktadır. İncelenen tematik konut projelerine bakıldığında; kentsel olgudan ve kentin bütünleşik mimarisinden ayrılan bir biçim kurgulandığı söylenebilir. Bu noktada projelerde yer alan kentin ve/veya tasvir edilen herhangi bir imajın "yeniden var olma biçimi", simülasyon (taslama) ilkesi ile ilişkilenmektedir. Böylelikle her şeyi taklit etme ve yapar gibi yapma yaklaşımının sonucunda "taklit edilmeyecek orijinal hiçbir şey yoktur" olgusuna ulaşılmıştır (Şekil 13-14). 


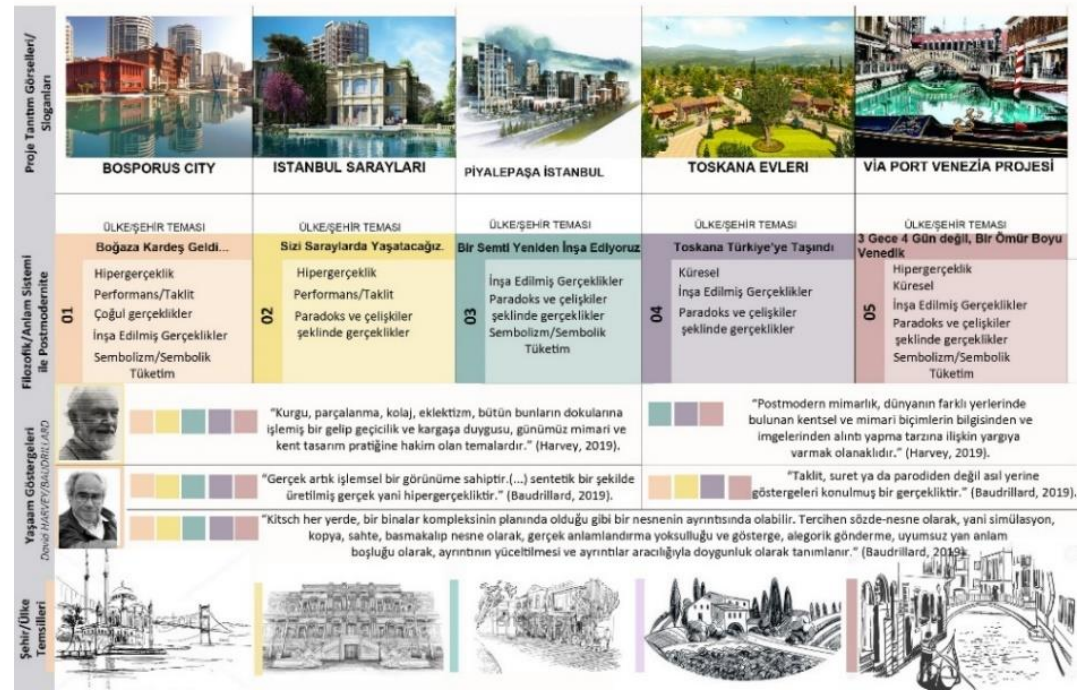

Şekil 13. Temalı Konut Projeleri Haritalama. Proje örneklem dizisi 01-05 (Söylem alıntı: Harvey, 2019 ve Baudrillard, 2019). Yazar tarafından oluşturuldu

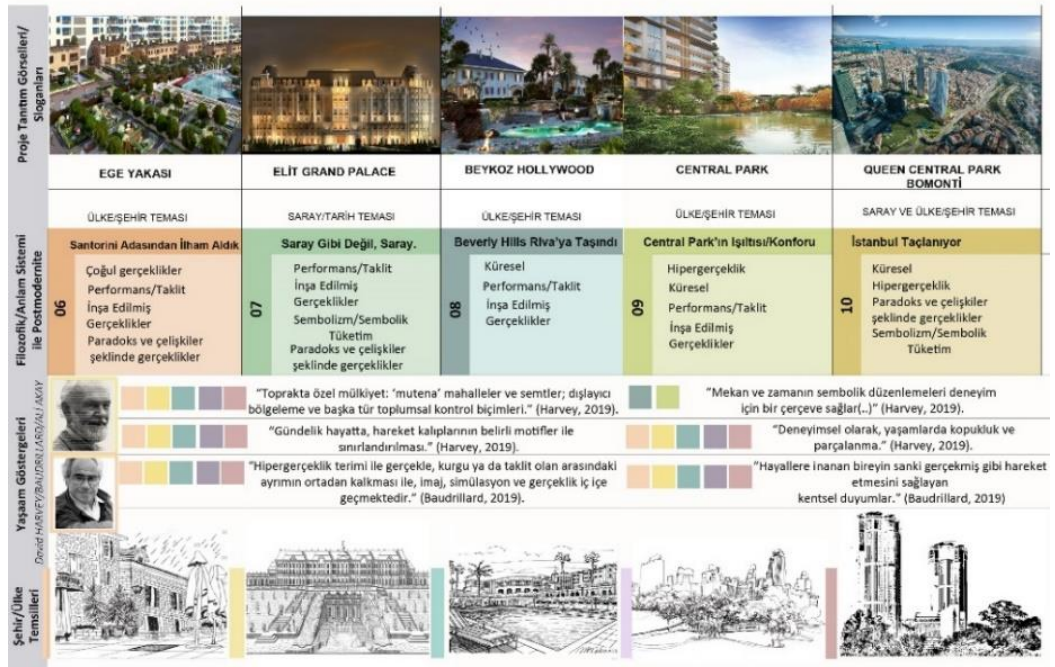

Şekil 14. Temalı Konut Projeleri Haritalama. Proje örneklem dizisi 06-10 (Söylem alıntı: Harvey, 2019 ve Baudrillard, 2019). Yazar tarafından oluşturuldu

Meta-göstergelerin medya iletişim araçları ile ön plana çıkarılması sonucunda projelerde yer alan imaj ve söylemlerin bir ifade dili kurgulaması söz konusudur ve bu dil toplum genelinde kolektif çağrışımlar oluşturmaktadır. Oluşturulan çağrışımlar, tüketicide gündelik yaşam pratikleri ile bir etkileşim sağlamamaktadır ve tüketici burada edindiği konut üzerinden bir kimlik ve 
gösterge kazanımına yönlendirilmektedir. Bu yönlendirme içerisinde tüketicinin konuta dair talep, beklenti ve kişisel isteklerini göz ardı etmesi söz konusu olmaktadır. Tüketiciye sunulan imajlar doğrultusunda tüketici artık kendisini İtalya'nın ya da Ege'nin bir kasabası, hatta Venedik, New York, Beverly Hills'de yaşamanın çok da uzağında görmemektedir. Bu durum da Baudrillard (2019)' in postmodern kent nosyonuna yönelik "parçalanmış" yapısı söylemi ile ilişkilenmektedir. Postmodern kent kültürü içerisinde oluşan bu kent metaforları veya gösteri olarak oluşturulan imgesel temalar etkisindeki "yeni yaşam biçimleri" parçalanarak çoğul hipergerçekliklere dönüştürülmektedir. Kentsel bütünlükte bakıldığında ise projelerin kent içeriğinden bağımsız hipergerçekliklere dayanması, postmodernitenin kenti estetikleştirmesi kavramı ve kent nosyonunun bağlamından uzak bir içeriğe dönüş(türül)mesi sonucunu ortaya koymaktadır.

\section{Tartışma ve Sonuç}

Kentin ve kentlinin bir bütünlük içerisinde değerlendirildiği kent tasarımları artık tüketim kültürünün etkisi ile hedonik bir yapıya dönüşmektedir ve kent "kentin estetikleştirilmesi" kavramı altında postmodern nosyonlara dayalı sonsuz bir dizi simülasyon etkisi altına girmektedir. Bu durum "gerçek" anlay1şını "hipergerçeklik" kavramı çerçevesine alarak gerçek, kurgu ve taklit arasındaki "akıl" yolu ile kavranabilirliği etkisiz kılmaktadır. Postmodernizmin belirleyici özelliği sayılan "parçalanma", geliştirilen temalar ile çoğul gerçekliklere evrilmektedir. Yeni yaşam biçimleri, kültürel ve bireysel olarak değerlendirildiğinde ise temalı konut projelerindeki yaşam senaryosunun ülke/şehir tasviri, tarihi simgesellik ve hayal, gerçek ikililiğindeki oluşumlar doğrultusunda hipergerçeklik üzerine kurulu olduğu görülmektedir. Böylece, oluşturulan parçalı hipergerçeklikler ile kentler simulakrlara dönüştürülmektedir. Kent bu noktada, tüketimi etkin kılma amaçlı oluşturulan ve bağlamından uzaklaşan bir hal almaktadır. Metropol kent yaşamındaki postmodern yaşam göstergeleri ise konut projelerindeki ülke temsilleri, medya imajları ve reklam söylemleri ile toplumu bağlamından kopuk bir mekânsal alg1 sürecine yönlendirmektedir. Parçalanma ile oluşturulan kurgu yaşamlar içerisinde birey, ülke ve kent temalarını kentten izole deneyimlerken, tüketim örüntüsü içerisinde yeni üretilecek gerçeküstü gerçeklikleri beklemektedir. Sonuç olarak, yeni yaşam arayışının tanımlanmasında süregelen ve geleceğe dönük oluşturulacak konut üretimlerinde içeriğin ve göstergenin hangi bağlamda ele alınacağının sorgusu önemli bir tartısma alanı olarak belirtmektedir. 


\section{Extended Abstract}

\section{Postmodern Indicators of the Advertising Language Used in Themed Housing Projects in Urban Life}

\author{
Çiğdem Karabă̆ \\ ORCID: 0000-0003-1590-9172
}

\author{
Esin Hasgül \\ ORCID: 0000-0003-4115-1940
}

The city in the context of consumption, interactions in daily life and all expressions formed within the framework of leisure activities are effective concepts used in the analysis of urban life. These formations, realized with the concept of postmodernity, are reflected in the architectural form effecting the socio-cultural context. While considering the urban designs in the city as a holistic point of view, the endless series of simulation situations dissociate the urban pattern. Postmodern notions under the concept of "aestheticizing the city" are transforming into a hedonic structure with the effect of consumer culture. These changes in the urban pattern of the city and the copy-paste construction installed in artificial environments, evoke the theories of important philosophers such as Baudrillard and Harvey. With the power of capitalism, the influence of consumer culture has increased considerably. Within the effects of postmodern consumption culture in architectural form, consumption action has become a need to express individuals' belonging to a social class. Thus, the aesthetic level of life becomes an evidence of "aestheticizing the city" concept. In this sense, transformations in housing projects are also the indicators of social and cultural changes. The trend that emerged in the texture of cities has been transformed into a model that operates under the themed housing projects. The constructed indicators and images configure a relation with the concept of "hyperreality". Formations which took place within the context of postmodern understanding, emphasize the creation of collage cities. The life presented through images and the scenario pre-constructed provide the consumer simulation examples such as landmarks taken from various geographies. 
The consumption culture that accelerated in the practice of the urban environment opens up the discussions of architectural and social segregation in society. The transformations have determined a hedonist approach by affecting the individual in a socio-psychological context. Being the subject of the consumption culture, the individual has lost the control to distinguish the reality from hyperreality while being manipulated by the effects of the codes, symbols and effective discourses presented in the media. Collective connotations have been realized by creating a language of expression with images and discourses. To do so, the meta-indicators are brought to the fore with media communication tools. Landmarks, which are located in the city with fragmented constructions, create a sense of being "nowhere but everywhere". Today, this notion of design has become an organization in which individuals' lives are guided and controlled through consumption patterns. These patterns appear in the context of commercialization of space and aesthetic presentation of daily life. With all these interactions, the repetitive and decontextualized productions cause the world to be understand in a different way of perception. The housing productions are one of the significant indicators in which the concept of "hyperreality" is being proposed to the consumers.

In line with the problematic stated in the study, multiple housing project productions which have the theme contents in their discourses are being examined. Productions made between the years 2000-2020, the theme content in written and visual published in the media and the location of housing projects in the city of Istanbul are determined as selection criteria of the projects. The selected 10 projects are analysed with "discourse analysis" method. Projects containing themed advertisements are examined through the housing project images, project explanation texts and promotional films. Thus, the reflections of the advertising language surrounding the architectural style of the postmodern consumer culture with an eclectic understanding is revealed. It is observed that the projects in the consumption culture, which are tried to be made more real than the truth by copying everything, are launched with the simulative presentations. Life presented in the light of the slogans in the advertisements are linked to the postmodernity concepts that Baudrillard and Harvey discussed. The discourses point out to form the comments and ideas about the formation of spatial and social identities by associating them with themes. The copy-paste configurations are shared with the similar interactions or contradictions of philosophical / semantic conceptualizations of postmodernity with the media. The concepts, themes and project slogans are analyzed in this context and the findings through the images and indicators are searched beyond ritual. 
With the simulation principle, which is distinguished from the urban phenomenon and the urban architecture integrated with it, leads the search for the expression of "the city itself". Thus, the principle of "there is nothing original to imitate" is a significant discussion topic where the postmodern indicators of the advertising language in urban life can be examined.

\section{Kaynakça/References}

Ağaoglu İnşaat (2017). Central Park Bakrrköy [Proje tanitım metni]. 5 Aralık 2020 tarihinde https://www.centralparkistanbul.com.tr/\#bize-ulasin adresinden erişildi.

Akay, A. (2013). Postmodernizmin ABC'si. İstanbul: Say Yayınları, 2. Baskı.

Aras, L. (2014). Bir mimarlık bilinmeyeni: Postmodern gündelik yaşamda 'konut' tükendi mi?, Megaron, 9(2), 103-112.

Babacan M. ve Onat F. (2002). Postmodern pazarlama perspektifi. Ege Akademik Bakış Dergisi.

Bal, H. (2018). Kent sosyolojisi. Bursa: Sentez Yayınları, 3. Baskı.

Bedirhan A. (2016). İdeal ev mitosuyla hayaller ve düşler ülkesinde yaşa(t)mak: lükse konut reklamlarının eleştirel bir analizi. İstanbul Journal of Social Sciences, 12.

Berger, J. (2019). Görme biçimleri. (Y. Salman, Çev.). İstanbul: Metis Yayınları, (Orjinal eserin yayın tarihi 1972).

Baudrillard, J. (2019). Tüketim toplumu. (N. Tutal, F. Keskin, Çev.). İstanbul: Ayrıntı Yayınları. (Orjinal eserin yayın tarihi 1970).

Baudrillard, J. (2018). Simülakrlar ve simülasyon. (O. Adanır, Çev.). Ankara: Doğubatı Yayınları. (Orjinal eserin yayın tarihi 1982).

Bauman, Z. (2018). Küreselleşme. İstanbul: Ayrıntı Yayınları, 8. Basım. (Orjinal eserin yayin tarihi 1998).

Batı, U. (2018). Tüketici dauranısları. İstanbul: Alfa Yayınları, 2.Basım.

Bat, U. (2019). Reklamin dili. İstanbul: Alfa Yayınları, 5.Basım.

Bat, U. (2008). Kentin postmodernitesi: postmodern tüketim kültürü 1ş̧̆̆ında hedonik bir biçim olan kent tasarımı. İstanbul Kültür Üniversitesi Güncesi, 5(4), 1-16.

Barthes, R. (1999). Göstergebilimsel serüven. (Çev. Mehmet Rufat ve Sema Rufat). İstanbul: Kaf Yayınları. 4.Basım.

Bayraktar İnşaat (2015). Viaport Venezia [Proje tanıtım metni]. 5 Aralık 2020 tarihinde http://www.bayraktarinsaat.com.tr/tr/proje/viaport-venezia-42 adresinden erişildi.

Benjamin, W. (1993). "Mekanik yeniden üretim çağında sanat eseri." (Çev. Hakkı Hünler). Edebiyat Eleştiri-Postmodernizm ve Politika Özel Sayıss: 77-78.

Buck-Morss, S. (1992). Aesthetics and anaesthetics: Walter Benjamin's artwork essay reconsidered. October, 62, 3-41.

Çinçin, K. S. (2018). Erken 21. Yüzyllda mekansal ve toplumsal kimliklerin değişimini büyük ölçekli konut projeleri reklamları üzerinden okumak. Mimarlık ve Yaşam Dergisi, 3(1), (1-20). 
Delmar (2011). Elit Grand Palace [Proje tanitım metni]. 5 Aralık 2020 tarihinde http://www.elitgrandpalas.com/index.asp adresinden erişildi.

Delmar Yapı. (2011). Elit Grand Palace tantım videosu [Tanıtım filmi]. 5 Aralık 2020 tarihinde https://www.youtube.com/watch?v=TNDQWvF8V-4 adresinden erişildi.

Dost Beykoz. (2016). Beykoz'da Hollywood Rüzgarı Esecek [Tanıtım filmi]. 5 Aralık 2020 tarihinde https://youtu.be/B9R5QffTLLE adresinden erişildi.

Emaar (2016). Toskana Vadisi [Proje tanitım metni]. 5 Aralık 2020 tarihinde https://www.emaar.com.tr/projeler/tuscan-valley adresinden erişildi.

Emlak Haberleri. (2015). Piyalepaşa İstanbul konut projesi [Tanıtım filmi]. 5 Aralık 2020 tarihinde https://www.youtube.com/watch? $\mathrm{v}=\mathrm{kXkOUQRczzM}$ adresinden erişildi.

Emlak Lobisi. (2020). Queen Central Park konut projesi [Tanıtım toplantıs1]. 5 Aralık 2020 tarihinde https://www.youtube.com/watch? $\mathrm{v}=\mathrm{u} 8 \mathrm{oujOu} 5 \mathrm{f} \times 4$ adresinden erişildi.

Emlak Rotası. (2014). Toskana Vadisi 3.Faz tanttm filmi [Tanitım filmi]. 5 Aralık 2020 tarihinde https://www.youtube.com/watch?v=BYBoTPMvPgU adresinden erişildi.

Eyfel Yapı (2016). Toskana Vadisi [Proje tanıtım metni]. 5 Aralı 2020 tarihinde https://dostbeykoz.com/beykoz-da-hollywood-ruzgari-esecek adresinden erişildi.

Gön, A. (2017). Hiçbir-Yer' de yaşam: Konut proje görselleri. İlef Dergisi, 4,2, 67-88.

Güleç, M. (2019). Modernleşmenin yaşam tarzı ve beğeni yargilarına etkisi bağlamında konut reklamlarının analizi. Aksaray Üniversitesi, İletişim Fakültesi, Aksaray İletişim Dergisi, 1(1).

Karapınar, A. (2017). Gerçeklik ve hiper gerçeklik; Baudrillard ve G. Debord anlatilanlardan hareketle "hakikatin yeniden inşası". Uluslararası Sosyal Araştırmalar Dergisi, 10(53).

Kırılmaz, H. ve Ayparçası, F. (2016). Modernizm ve postmodernizm süreçlerinin tüketim kültürüne yansımaları. Insan Ėंnsan, 8, 32-58.

Harvey, D. (2019). Postmodernliğin durumu. İstanbul: Metis Yayınları, 8.Basım. (Orjinal eserin yayın tarihi 1990).

Kılıç, H. ve Ayataç, H. (2019). Konut sunum biçimlerinin İstanbul'un sosyokültürel ve mekansal değişimlerine etkileri. Megaron, 14 (suppl.1), 109-121.

Mood Production. (2016a). // Bosphorus City // Yüzücü // Tvc [Tanıtım filmi]. 5 Aralık 2020 tarihinde https://www.youtube.com/watch?v=6ipg2xWdUmg adresinden erişildi.

Mood Production. (2016b). // Istanbul Sarayları // Tvc [Tanitım filmi]. 5 Aralık 2020 tarihinde https://www.youtube.com/watch?v=ulOso-7v5xQ adresinden erişildi.

Odabaşı, Y. (2017). Postmodern pazarlama. İstanbul: Mediacat Yayınları, 5.Basım.

Oktay, D. (2011). Kent kimliğine bütüncül bir bakış. İdeal Kent Dergisi, 3, 8-19.

Özcan, B. (2007). Hedonizm ve kimlik temeline dayalı postmodern tüketim yaklaşımı. İstanbul Üniversitesi İktisat Fakültesi İktisat Bölümü.

Özoran, A. B. (2019). Yeni bir yaşama ve yeni bir düşünce biçimi: postmodern kültür. Uluslararası Sosyal Araştırmalar Dergisi, 12(62).

Perouse, F. J. ve Danış, D. A. (2005). Zenginliğin mekânda yeni yansımaları: İstanbul'da güvenlikli siteler. Toplum ve Bilim, 104. 
Polat İnşaat. (2019). Piyalepaşa İstanbul Konut Projesi [Proje tanitım metni]. 5 Aralık 2020 tarihinde https:/www.piyalepasa.com.tr/assets/docs/piyalepasa2-tr/ adresinden erişildi.

Proje Konutları. (2016). Viaport Venezia Bayraktar Inşaat [Tanıtım filmi]. 5 Aralık 2020 tarihinde https://www.youtube.com/watch?v=QM4FIMw4FTU adresinden erişildi.

Projede Firsat. (2017). Agaoglu Central Park Projesi [Tanıtım filmi]. 5 Aralık 2020 tarihinde https://www.youtube.com/watch?v=I_dx6x6ZE-o adresinden erişildi.

Robins, K. (2013). İmaj. (Çev. Nurçay Türkoğlu). İstanbul: Ayrıntı Yayınları, 2. Basım.

Sinpaş GYO (2016). Queen Central Park Konut Projesi [Proje tanitım metni]. 5 Aralık 2020 tarihinde https://queenbomonti.com adresinden erişildi.

Sinpaş GYO (2019a). Bosphorus City [Proje tanıtım metni]. 5 Aralık 2020 tarihinde https://www.sinpas.com.tr/projeler/bosphorus-city adresinden erişildi.

Sinpaş GYO (2019b). Istanbul Sarayları [Proje tanıtım metni]. 5 Aralı 2020 tarihinde https://www.sinpas.com.tr/projeler/istanbul-saraylari adresinden erişildi.

Sinpaş GYO (2019c). Ege Yakası [Proje tanıtım metni]. 5 Aralık 2020 tarihinde https://www.sinpas.com.tr/projeler/ege-yakasi adresinden erişildi.

Solak, G. S. ve Oktay, E. (2017). “Konut”tan öte “Konut”tan ziyade: Yaratılan yeni kentsel ütopyaların konut reklamları aracılığıyla inşası. Mustafa Kemal Üniversitesi, Sosyal Bilimler Dergisi, 14(40).378-397.

Soygeniş, S. (2017). Mimarlık düşünmek düşlemek. İstanbul: Yem Yayınları, 6.Basım.

Süer, D. ve Sayar Y. (2002). Küresel sermayenin yeni tüketim mekânları lüks konut siteleri. Çağdaş Mimarlık Sorunları, Mimarlık ve Tüketim, Boyut Yayın Grubu, 39-66.

Şahin, P. ve Şener M. S. (2018). Türkiye' de konut söylemlerinde yaşanan değişimin reklamlar üzerinden analizi İstanbul örneği. İdealkent, 9(23).

Taşar, S. (2008). Mekansal imge yaratmada medyanın rolü "küresel" İstanbul'da (lüks) konut reklamları. Yüksek Lisans Tezi. Dokuz Eylül Üniversitesi, İzmir.

Yeni Projeler. (2014). Sinpaş Eviya Gayrimenkul Ege Yakası [Tanıtım filmi]. 5 Aralık 2020 tarihinde https://www.youtube.com/watch?v=BVGH-SP5EIk adresinden erişildi.

Yırtıcl, H. (2002). Tüketimin mekansal örgütlenmesinin ideolojisi. Çă̆daş Mimarlık Sorunları, Mimarlk ve Tüketim, Boyut Yayın Grubu, 9-38. 